\title{
Identification of inadvertently removed parathyroid glands during thyroid surgery using autofluorescence
}

\author{
Carlos Serra $^{1,2}$, Luís Silveira ${ }^{3}$, António Canudo ${ }^{1}$ \\ ${ }^{1}$ Department of Surgery, SAMS Hospital, Lisbon, Portugal; ${ }^{2}$ Health Sciences Research Centre (CICS-UBI), ${ }^{3}$ Faculty of Health Sciences, University \\ of Beira Interior, Covilhã, Portugal \\ Contributions: (I) Conception and design: All authors; (II) Administrative support: C Serra, A Canudo; (III) Provision of study materials or patients: C \\ Serra, A Canudo; (IV) Collection and assembly of data: C Serra, A Canudo; (V) Data analysis and interpretation: C Serra, L Silveira; (VI) Manuscript \\ writing: All authors; (VII) Final approval of manuscript: All authors. \\ Correspondence to: Carlos Serra. Department of Surgery, SAMS Hospital, Rua Cidade de Gabela, 1, 1800-052 Lisbon, Portugal. \\ Email: caaserra@me.com.
}

Background Incidental excision of parathyroid glands is a common event during thyroid surgery and in
spite the divergent results that can be obtained from the literature about its clinical significance, all efforts
must be used to their preservation. Due to the autofluorescence emitted by parathyroid glands, authors
began to use a custom device to inspect thyroidectomy specimens for incidentally removed parathyroid
tissue; the results of using this device are presented in this manuscript.
Methods: Specimens of 40 consecutive thyroid surgeries were inspected. Localization of suspect high-
fluorescence spots were recorded for confirmation with a pathological exam. Determinations of calcium and
parathyroid hormone (PTH) were completed prior to surgery and at 24 hours and 15 days after the operation.
Results: Patient age ranged from 36 to 83 years and were predominantly female (82.5\%). Calcium values
at 24 hours post-operation varied between 7.1 and 9.5 . The PTH values ranged between 3 and 77 . Thirteen
patients (32.5\%) presented with biochemical hypocalcemia at 24 hours. At 15 days after the operation, only
one patient presented with a calcium value below 8 (PTH: 10.9 ) with complete normalization 6 months after
the surgery. Pathological examination identified eight parathyroid fragments in seven patients. There was
no correlation between the presence of parathyroid tissue in the specimen and post-operative hypocalcemia
(P=0.254). Eight suspicious areas of augmented fluorescence where detected; seven were coincident with the
pathological examination and one was a false positive. One intrathyroidal gland was not identified, resulting
a sensitivity of $87.5 \%$ and specificity $96.2 \%$.

Conclusions: Although no correlation between incidental parathyroidectomy and hypocalcemia was demonstrated, autofluorescence may be a useful tool for in-table identification of incidentally-removed glands.

Keywords: Autofluorescence; incidental parathyroidectomy; parathyroid; thyroid surgery

Submitted Jan 27, 2020. Accepted for publication May 27, 2020.

doi: $10.21037 /$ gs-20-163

View this article at: http://dx.doi.org/10.21037/gs-20-163

\section{Introduction}

In 2011, Paras was the first to describe autofluorescence of the parathyroid glands, a property that could be useful for their discrimination from other cervical tissues including lymph nodes and fat (1). Since that publication, other authors confirmed the utility of autofluorescence of the parathyroid during thyroid and parathyroid surgeries (2-4). Parathyroid glands exposed to a near infrared light

^ORCID: 0000-0003-3320-3464. 
(700-800 $\mathrm{nm})$ also emit autofluorescence in the infrared spectra $(822 \mathrm{~mm})$. Thyroid glands also emit autofluorescence but at lower intensity, allowing the discrimination between the tissues (1).

Although promising, the method only allows identification of parathyroid glands without providing information about the functional status of the glands. Nevertheless, improved capacity for identifying the parathyroid glands could be the first step for the preservation of the tissue and thus their function.

The systematic search for parathyroid glands during thyroid surgery could increase the operative time and in some cases endanger the glands that are outside the direct operative field. This identification may force an unnecessary, extended dissection (5). The autofluorescent nature of the parathyroid glands could also be useful for identification of inadvertently removed glands during thyroid surgery or cervical lymph node dissection, allowing their immediate or delayed auto-transplant.

Incidental parathyroidectomy is a frequent event during thyroid surgery, occurring in $6.4 \%$ to $31.1 \%$ of cases (6). Those rates have the potential to be decreased with a meticulous surgical technique, but complete elimination of inadvertent removal of parathyroid tissue will depend of the development of a system capable of identifying all the glands, including rare intrathyroidal tissues. The clinical significance of the incidental removal of single gland is not obvious; the traditional idea that the presence of one well-perfused parathyroid gland may be sufficient for maintaining calcium homeostasis has not been rebutted (5).

However, surgeons generally treat every parathyroid gland as if it is the patient's last, so that all efforts to minimize their incidental removal are emphasized $(7,8)$. Due to the high cost of commercially available devices for detecting autofluorescence, we developed a goggle-based, easily reproducible system using common gadgets that we have used in our daily practice (9). In this manuscript, we present results of using this system for inspection of the removed thyroid specimen for detecting inadvertently removed parathyroid glands under conditions that could allow for subsequent auto-transplant.

We present the following article in accordance with the STROBE reporting checklist (available at http://dx.doi. org/10.21037/gs-20-163).

\section{Methods}

All procedures were performed in accordance with the ethical standards of the institutional review board (approval from Comissão de Ética do Hospital dos SAMS, 002/2018) and with the 1964 Helsinki declaration and its later amendments (as revised in 2013) or comparable ethical standards. Informed consent was obtained from all individual participants included in the study.

Forty patients ( 33 females, 7 males) with ages ranging from 36 to 83 (mean: 59.5, SD: 12.59) years were submitted for thyroid resection surgery. A total of 34 total thyroidectomies (seven with a thoracic component), four lobectomies, and two completion thyroidectomies were performed by the same surgeon, a general surgeon with particular interest in endocrine surgery and a practice of 50 thyroidectomies per year on average.

Removed specimens were inspected in a sterile environment for the presence of inadvertently excised parathyroid glands using our device composed of an emission light emitting diode (LED) and an image acquisition system.

With the room lights turned off, the specimen was submitted to a $780 \mathrm{~nm}$ light beam, emitted by a LED Thorlabs Model M780L-C1 (Thorlabs GmbH, Dachau, Germany) with a bandpass excitation filter of $769( \pm 41) \mathrm{nm}$ Edmund Optics 84123 (Edmund Optics, Barrington, NJ, USA), powered by a LED driver T-cube $1,200 \mathrm{~mA}$ (Thorlabs GmbH, Dachau, Germany). Simultaneously, the irradiated area was visualized through the image acquisition system composed of a iGEN Night Viewer 20/20 Night Owl night vision goggle device (Night Owl Optics, El Paso, TX, USA), with an Edmund Optics 84123 bandpass acquisition filter of $832( \pm 28) \mathrm{nm}$ (Edmund Optics, Barrington, NJ, USA), seeking high fluorescence areas that could represent parathyroid tissue (Figures 1,2).

Localization of suspect high fluorescent areas was recorded for confirmation with the results of the regular pathological exam.

Determinations of serum calcium and parathyroid hormone (PTH) were performed prior to surgery and were measured 24 hours and 15 days after surgery. For statistical analysis of data, IBM SPSS Statistics V.22 (IBM Corp. Released 2013. IBM SPSS Statistics for Macintosh, Version 22.0. Armonk, NY: IBM Corp) software with Student's $t$-test and chi-square tests were used. A level of significance of 0.05 was used.

\section{Results}

Demographic, pathological, and operative data are shown 


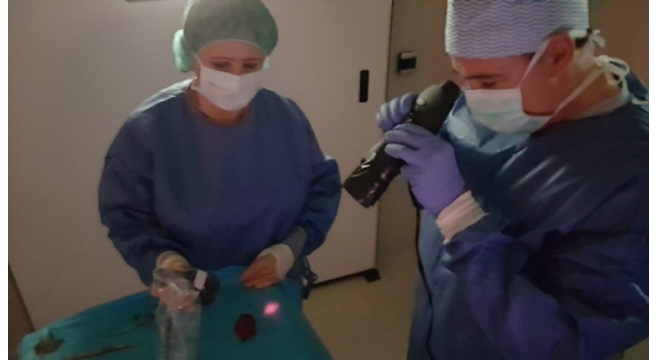

Figure 1 Inspection of thyroidectomy specimen.

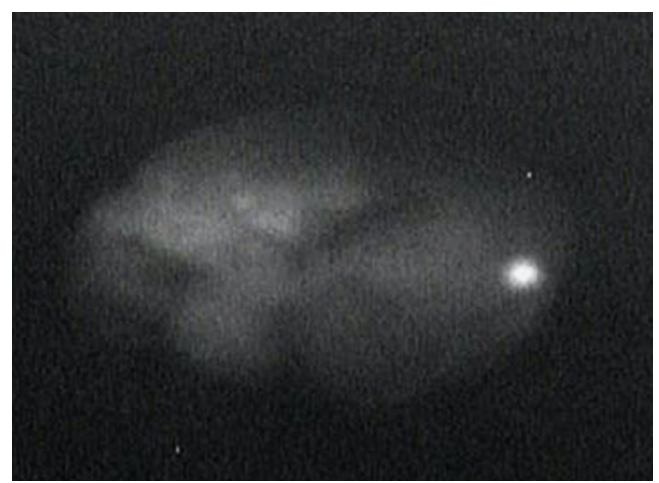

Figure 2 Parathyroid fragment (bright spot) on a heterogeneous thyroid lobe.

in Table 1. Pre-operative values calcium ranged from 8.6 to 10.2 (mean: 9.45 , SD: 0.35 ) mg/dL. Preoperative PTH ranged from 22.9 to 103.0 (mean: 53.38, SD: 23.63 ) pg/mL. If only complete thyroidectomies were considered, preoperative calcium and PTH means and SD were 9.36 (0.12) $\mathrm{mg} / \mathrm{dL}$ and 56.55 (24.60) $\mathrm{pg} / \mathrm{mL}$ respectively.

Values of calcium at 24 hours after surgery varied between 7.1 and 9.5 (mean: 8.23 , SD: 0.51 ) $\mathrm{mg} / \mathrm{dL}$ for the all samples. For total and complete thyroidectomies, calcium values held a mean and SD 8.23 and 0.52 , respectively. PTH values at 24 hours post-operation varied between 3 and 77.0 (mean: 33.41, SD: 22.30) pg/mL. Total thyroidectomies and completion thyroidectomies had a mean PTH of 33.33 and a SD of 22.83. The incidence of biochemical hypocalcemia at 24 hours was $32.5 \%$ (12 on total or completion thyroidectomies, 1 on lobectomy, $\mathrm{P}=0.608)$.

The study was however underpowered to detect hypocalcemia $(\pi=0.085)$.

Post-operative day 15 calcium values were between 7.9 and $10.4 \mathrm{mg} / \mathrm{dL}$ (mean: 9.9, SD: 0.50 for all samples and
Table 1 Demographic, pathological and operative data

\begin{tabular}{|c|c|c|c|c|}
\hline Variables & $\begin{array}{c}\text { Number of } \\
\text { patients (\%) }\end{array}$ & $\begin{array}{c}\text { Number of } \\
\text { patients (\%) } \\
\text { with IPS }\end{array}$ & P value & $\begin{array}{l}\text { Test } \\
\text { value }\end{array}$ \\
\hline \multicolumn{5}{|l|}{ Sex } \\
\hline Male & $7(17.5)$ & $2(28.5)$ & 0.408 & 0.415 \\
\hline Female & $33(82.5)$ & $5(15.2)$ & & \\
\hline \multicolumn{5}{|l|}{ Surgery } \\
\hline Total/completion & $36(90.0)$ & $7(18.4)$ & 0.448 & 0.943 \\
\hline Hemithyroidectomy & $4(10.0)$ & 0 & & \\
\hline \multicolumn{5}{|l|}{ Thoracic goiter } \\
\hline Yes & $5(12.5)$ & 0 & 0.283 & 0.174 \\
\hline No & $35(87.5)$ & $7(20.0)$ & & \\
\hline \multicolumn{5}{|l|}{ Malignancy } \\
\hline Yes & $7(17.5)$ & $2(28.5)$ & 0.355 & 0.720 \\
\hline No & $33(82.5)$ & $5(15.2)$ & & \\
\hline \multicolumn{5}{|l|}{ Thyroiditis } \\
\hline Yes & $6(15.0)$ & $1(16.7)$ & 0.721 & 0.003 \\
\hline No & $34(85.0)$ & $5(14.7)$ & & \\
\hline \multicolumn{5}{|l|}{$24 \mathrm{~h}$ hypocalcemia } \\
\hline Yes & $13(32.5)$ & $1(7.6)$ & 0.254 & 1.283 \\
\hline No & 27 (67.5) & $6(22.2)$ & & \\
\hline
\end{tabular}

IPS, incidental parathyroid tissue on specimen.

mean: 9.21, SD: 0.09 when excluding lobectomies). At day 15 after surgery, PTH ranged between 7.1 and $156 \mathrm{pg} / \mathrm{mL}$ (mean: 49.149, SD: 33.45). Mean and SD when excluding lobectomies were 51.97 and 34.05, respectively.

At day 15, one patient had a calcium level below $8.0 \mathrm{mg} / \mathrm{dL}$, with a PTH of $10.9 \mathrm{pg} / \mathrm{mL}$. At day 180 those values were normal, with a calcium score of $8.9 \mathrm{ng} / \mathrm{dL}$ and a PTH of $24.0 \mathrm{pg} / \mathrm{mL}$.

Pathological examination revealed a malignancy in seven samples, including six papillary carcinoma and one medullary carcinoma.

Medium weight of specimens was 55.17 (SD: 32.56) $\mathrm{g}$ for total thyroidectomies and 21.75 (SD: 6.946) $\mathrm{g}$ for lobectomies. In 6 samples $(15 \%)$ there were features of lymphocytic thyroiditis.

Pathological examination of the resection specimen identified parathyroid tissue in eight samples from seven patients, all of which were submitted for total 
Table 2 Parathyroid glands on sample

\begin{tabular}{lccccccccc}
\hline Patient & Sex & Age & Diagnosis & Pt S & Pt AF & C/P & Loc & Suspection & Hypocalcemia \\
\hline 1 & M & 79 & Multinodular goiter & 1 & 1 & P & EC & No & No \\
2 & F & 70 & Multinodular goiter & 1 & 1 & P & EC & No & No \\
3 & M & 73 & Normal thyroid (totalization) & 1 & 1 & P & EC & No & No \\
4 & F & 62 & Multinodular goiter & 2 & 1 & P; C & IC; IT & No no \\
5 & F & 66 & Papillary carcinoma & 1 & 1 & P & IC & No & No \\
6 & F & 36 & Multinodular goiter & 1 & 1 & P & IC & No & No \\
7 & F & 38 & Multinodular goiter & 1 & 1 & P & EC & Yes & Yes \\
\hline
\end{tabular}

M, male; F, female; Pt S, number of parathyroid glands found on pathological exam; Pt AF, number of parathyroid glands found by autofluorescence; C, complete gland; P, fragment of gland; Loc, localization regarding thyroid gland; EC, extracapsular; IC, Intracapsular; $\mathrm{IT}$, intrathyroidal (surrounded by parenquima).

thyroidectomies. One specimen had two intrathyroidal parathyroid glands.

Only one patient with incidental parathyroidectomy had 24-hour post-operative hypocalcemia, with PTH in the normal range, and normalization of calcium on postoperative day 15 . There was no correlation between the presence of parathyroid tissue in the sample and 24-hour post-operative hypocalcemia $(\mathrm{P}=0.254)$. There was also no correlation between the presence of parathyroid tissue and the type of surgery $(\mathrm{P}=0.344)$, pathological diagnosis $(\mathrm{P}=0.409)$, presence of lymphocytic thyroiditis $(\mathrm{P}=0.955)$, or substernal goiter $(\mathrm{P}=0.283)$.

Across the whole sample there were eight suspicious areas with a significant increase in fluorescence but only one was considered suspicious by the surgeon. Subsequent pathological examination confirmed seven of these tissues as parathyroid tissue. There was one false positive (colloid nodule). In spite of maintaining conditions for autotransplantation of parathyroid glands, the small volume of parathyroid tissue detected in the samples prevented transplantation.

Table 2 summarizes the characteristics of the patients with incidentally removed parathyroid tissue.

The system failed to identify one of the two intrathyroidal parathyroid glands present in a patient, identifying only the most superficial one (intracapsular) missing the deep situated one, localized $3 \mathrm{~mm}$ into the parenchyma.

Sensitivity and positive predictive value of the assay was $87.5 \%$ and specificity and negative predictive value were $97.1 \%$.

\section{Discussion}

Although intraoperative identification of all the parathyroid glands would be desirable, some parathyroid glands lay outside the thyroidectomy dissection field, resulting in a search that may cause an unnecessary extended dissection that can harm the blood supply of the glands (5). The visualization and maintenance of parathyroid glands in situ also doesn't provide information about the functional status of the glands, and post-operative hypocalcemia is still possible. Utilization of indocyanine green (ICG) can assess the vascularization of parathyroid glands, but doesn't completely predict post-operative hypocalcemia (10).

Visual inspection of the surgical specimen in search of inadvertently removed parathyroid glands is usually performed for the majority of the surgeons, allowing for immediate auto-transplantation.

The utilization of the device described by our study could identify all the extra-capsular glands and one of the two intrathyroidal glands. The inability to identify one of the intrathyroidal glands may be related to its deep anomalous localization and could represent a limitation of the system.

If compared with the FDA approved devices for parathyroid identification our system has the advantage of the low cost (less than 3,200 euros), making it affordable even for hospitals with scarce financial resources, and is easier to assemble than other custom-build devices that need significant technical intervention (11).

We considered the presence of parathyroid tissue in the thyroid specimen as inadvertent parathyroidectomy, although it may only represent partial or minimal tissue 
removal with maintenance of the remaining gland, as our usual extra-capsular thyroidectomy technique is particularly prone to parathyroid preservation. This may explain the limited impact we found on postoperative hypocalcemia in patients with parathyroid tissue in the specimen.

There are divergent results concerning the relation of incidental parathyroidectomy and occurrence of hypocalcemia. In a study of 158 patients, Sakorafas et al. did not observe this association (12), as McGoldrick did in a study of 230 cases (13). In this study, the presence of malignancy was found to increase the risk of inadvertent parathyroidectomy; we did not observe this with our smaller sample. Sitges-Serra et al. found greater rates of post-operative hypocalcemia in the inadvertent parathyroidectomy group in 170 cases of total thyroidectomies and central neck dissections for papillary thyroid carcinoma, suggesting that extended resections are a risk factor (14). A systematic meta-analysis including 35 studies conducted by Bai et al. concluded that malignancy, central neck dissection, and reoperation were significant risk factors for incidental parathyroidectomy and that incidental parathyroidectomy increases the risk of post-operative hypocalcemia after thyroidectomy (15).

Despite our results failing to show any relationship between the occurrence of incidental parathyroidectomy and post-operative hypocalcemia, decreasing the necessity of auto-transplant of incidentally removed glands, there is an evident advantage in knowing if there is any parathyroid tissue in thyroidectomy specimen. Presence of more than one fragment of parathyroid tissue might become an indication for auto-transplant.

The high sensitivity and specificity rates obtained with the utilization of autofluorescence showed the utility of the system that may function as an "optical biopsy" after proper validation.

For this preliminary study, we could not use the device for identification of parathyroid glands in situ during surgery, as the ethical committee approval did not include that utilization. In spite of not providing information about the vascularization of the parathyroid glands, an early awareness of their localization may help the surgeon to avoid their manipulation and to prevent devascularization. Thus the integration of intraoperative visualization of parathyroid glands with auto-fluorescence followed by in table inspection of the specimen could decrease rates of post-operative hypocalcemia as shown by the works of Kim et al. and the randomized controlled trials conducted by Dip et al. and Benmiloud et al. (16-18).
Further studies with larger sample sizes will help improve our understanding of this issue.

A relevant limitation of this study is the fact that all the surgeries were performed by the same surgeon, an experienced thyroid surgeon although not a high-volume surgeon, whose experience could be related to the little volume of the parathyroid fragments found.

As the majority of thyroid surgeries all-over the world are performed by low-volume surgeons, whom may benefit more of the assistance of autofluorescence for the identification of parathyroid glands, a study evolving surgeons with different levels of expertise would be useful, evaluating not only the results of postoperative hypocalcemia but also the effects on the learning curve.

\section{Conclusions}

Although in this study we could not demonstrate a relationship between incidental parathyroidectomy and postoperative hypocalcemia, the high sensitivity and specificity rates make autofluorescence of parathyroid glands an useful tool for identification of incidentally removed glands during thyroidectomy.

\section{Acknowledgments}

The authors want to thank Drs. Paula Guerra Marques, Sara Turpin and Delfina Brito of the Department of Pathology of Hospital dos SAMS for their contribution in this study.

Funding: None.

\section{Footnote}

Reporting Checklist: The authors have completed the STROBE reporting checklist. Available at http://dx.doi. org/10.21037/gs-20-163

Data Sharing Statement: Available at http://dx.doi. org/10.21037/gs-20-163

Peer Review file: Available at http://dx.doi.org/10.21037/gs20-163

Conflicts of Interest: All authors have completed the ICMJE uniform disclosure form (available at http://dx.doi. org/10.21037/gs-20-163). The authors have no conflicts of interest to declare. 
Ethical Statement: The authors are accountable for all aspects of the work in ensuring that questions related to the accuracy or integrity of any part of the work are appropriately investigated and resolved. All procedures were performed in accordance with the ethical standards of the institutional review board (Approval from Comissão de Ética do Hospital dos SAMS, 002/2018) and with the 1964 Helsinki declaration and its later amendments (as revised in 2013) or comparable ethical standards. This study is part of a $\mathrm{PhD}$ project and has been registered in a national (Portuguese) public database: https://renates2.dgeec.mec.pt (Project ID: 101602375), thus complying with the Declaration of Helsinki requirement for the registration of research.

Open Access Statement: This is an Open Access article distributed in accordance with the Creative Commons Attribution-NonCommercial-NoDerivs 4.0 International License (CC BY-NC-ND 4.0), which permits the noncommercial replication and distribution of the article with the strict proviso that no changes or edits are made and the original work is properly cited (including links to both the formal publication through the relevant DOI and the license). See: https://creativecommons.org/licenses/by-nc-nd/4.0/.

\section{References}

1. Paras C, Keller M, White L, et al. Near-infrared autofluorescence for the detection of parathyroid glands. J Biomed Opt 2011;16:067012.

2. McWade MA, Paras C, White LM, et al. A novel optical approach to intraoperative detection of parathyroid glands. Surgery 2013;154:1371-7.

3. Falco J, Dip F, Quadri P, et al. Cutting edge in thyroid surgery: autofluorescence of parathyroid glands. J Am Coll Surg 2016;223:374-80.

4. Ladurner R, Sommerey S, Arabi NA, et al. Intraoperative near-infrared autofluorescence imaging of parathyroid glands. Surg Endosc 2017;31:3140-5.

5. Chang YK, Lang BHH. To identify or not to identify parathyroid glands during total thyroidectomy. Gland Surg 2017;6:S20-9.

6. Vasileiadis I, Charitoudis G, Vasileiadis D, et al. Clinicopathological characteristics of incidental parathyroidectomy after total thyroidectomy: the effect on hypocalcemia. A retrospective cohort study. Int J Surg 2018;55:167-74.

7. Rogers-Stevane J, Kauffman GL Jr. A historical perspective on surgery of the thyroid and parathyroid glands. Otolaryngol Clin North Am 2008;41:1059-67, vii.

8. Halsted WS, Evans HM. I. The parathyroid glandules. Their blood supply and their preservation in operation upon the thyroid gland. Ann Surg 1907;46:489-506.

9. Serra C, Silveira L, Canudo A, et al. Parathyroid identification by autofluorescence - preliminary report on five cases of surgery for primary hyperparathyroidism. BMC Surg 2019;19:120.

10. Razavi AC, Ibraheem K, Haddad A, et al. Efficacy of indocyanine green fluorescence in predicting parathyroid vascularization during thyroid surgery. Head Neck 2019;41:3276-81.

11. Kim SW, Song SH, Lee HS, et al. Intraoperative realtime localization of normal parathyroid glands with autofluorescence imaging. J Clin Endocrinol Metab 2016;101:4646-52.

12. Sakorafas GH, Stafyla V, Bramis C, et al. Incidental parathyroidectomy during thyroid surgery: an underappreciated complication of thyroidectomy. World J Surg 2005;29:1539-43.

13. McGoldrick DM, Majeed M, Achakzai AA, et al. Inadvertent parathyroidectomy during thyroid surgery. Ir J Med Sci 2017;186:1019-22.

14. Sitges-Serra A, Gallego-Otaegui L, Suárez S, et al. Inadvertent parathyroidectomy during total thyroidectomy and central neck dissection for papillary thyroid carcinoma. Surgery 2017;161:712-9.

15. Bai B, Chen Z, Chen W. Risk factors and outcomes of incidental parathyroidectomy in thyroidectomy: a systematic review and meta-analysis. PLoS One 2018;13:e0207088.

16. Kim SW, Lee HS, Ahn YC, et al. Near-infrared autofluorescence image-guided parathyroid gland mapping in thyroidectomy. J Am Coll Surg 2018;226:165-72.

17. Dip F, Falco J, Verna S, et al. Randomized controlled trial comparing white light with near-infrared autofluorescence for parathyroid gland identification during total thyroidectomy. J Am Coll Surg 2019;228:744-51.

18. Benmiloud F, Godiris-Petit G, Gras R, et al. Association of autofluorescence-based detection of the parathyroid glands during total thyroidectomy with postoperative hypocalcemia risk: results of the PARAFLUO multicenter randomized clinical trial. JAMA Surg 2019;155:106-12.

Cite this article as: Serra C, Silveira L, Canudo A. Identification of inadvertently removed parathyroid glands during thyroid surgery using autofluorescence. Gland Surg 2020;9(4):893-898. doi: 10.21037/gs-20-163 